\title{
NUMERICAL STUDY OF MILK FOULING THICKNESS IN THE CHANNEL OF PLATE HEAT EXCHANGER
}

\author{
S. A. Aouanouk ${ }^{1, *}$, A. Mouheb ${ }^{1}$, R. Absi ${ }^{2}$
}

\begin{abstract}
Fouling phenomenon remains at the forefront of problems that concern manufacturers using heat exchangers. Despite the large number of studies carried out, the mechanism and the evolution of this phenomenon remain poorly understood. In the dairy industry, fouling is a very important parameter seen as it can affect the quality of food product. Studies carried out on this phenomenon during milk heat treatment have led to the conclusion that lacotglobulin protein is the main precursor of fouling. Indeed, the thermal instability of this protein undergoes chemical reactions generating an aggregate that accumulates on the hot walls of heat exchanger. In this work, an attempt to model, numerically, milk fouling during pasteurization was carried out. Wall temperature and fouling thickness distributions were studied along the channel. This permits to determine a mathematical relationship between fouling thickness and wall temperature.
\end{abstract}

\section{Keywords: Milk Fouling, Plate Heat Exchanger, Modeling}

\section{INTRODUCTION}

Thermal performance of plate heat exchanger is aggressively deteriorated during milk heat treatment by fouling phenomenon. In dairy industry, fouling is mainly due to chemical alteration of $\beta$-lactoglobulin protein, which will products deposits on walls of the equipment [1]. Since several years ago, studying and modeling milk fouling mechanism is very attractive investigation field. Toyoda and Fryer [2], proposed a fouling model that takes into account mass transfer occurred between fluid bulk and boundary layer. Georgiadis and Macchietto [3] established a two-dimensional mathematical model using fluid flow to predict, with more accuracy, the temperature distribution. Jun and Puri [4] developed the previous work into a dynamic 2D model to predict more precisely milk deposit patterns on the plate surface. Mahdi et al. [5] proposed a two-dimensional dynamic fouling model for milk fouling in a plate heat exchanger, which takes into account fouling caused by both $\beta$-lactoglobulin protein and calcium phosphate. Few studies have attempt on kinetics of $\beta$-lactoglobulin denaturation. The effect of calcium on $\beta$-lactoglobulin denaturation has been discussed by Petit et al. [6] and Erabit et al. [7], they conclude that high calcium concentrations catalyzes unfolding and aggregation reactions. Khaldi et al. [8] carried out experiments in order to determine the relationship between the deposit mass distribution generated in plate heat exchanger and the ratio between the unfolding and aggregation rate constants. Recently, Bouvier et al. [9] used CFD (Computational Fluid Dynamics) as a tool to simulate $\beta$-lactoglobulin heat induced denaturation and aggregation in plate heat exchanger. They demonstrated that the unfolded $\beta$-lactoglobulin is the main precursor generating a dry deposit on the heat transfer wall.

The present study consists of developing a model to describe evolution of the deposit amount accumulated on the channel walls of a plate heat exchanger during milk pasteurization. A calculation code is used to solve the equations of momentum, heat transfer and those governing the reactions and the mechanism of deposition on the walls. Evolution of deposit thickness as a function of time is studied. Also, an attempt to determine a mathematical relationship between the wall temperature and deposit thickness is presented in this work.

\section{MATHEMATICAL FORMULATION}

A computer code was developed in order to resolve equations governing transfer phenomenon and fouling model proposed that occur in the first channel of plate heat exchanger. We consider a rectangular geometry, as shown in Figure 1, composed by two parallel plates of $75 \mathrm{~cm}$ length and $20 \mathrm{~cm}$ width. The channel thickness is $\mathrm{e}$ $=4 \mathrm{~mm}$.

This paper was recommended for publication in revised form by Regional Editor Ahmed Kadhim Hussein

1 Transfer phenomenon laboratory, Chemical Engineering department, U.S.T.H.B. Algiers, Algeria.

2 School of Industrial Biology. 49 avenue des Genottes, 95800 Cergy-Pontoise. France

${ }^{*} E$-mail address: aouanouk.a@gmail.com

Manuscript Received 30 May 2017, Accepted 26 July 2017 


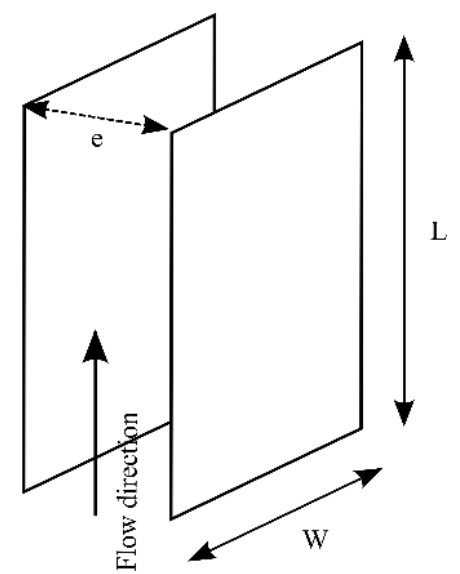

Figure 1. Descriptive scheme of the channel.

Assuming that fluid flow is laminar and incompressible in two-dimensional Cartesian coordinates, the physicochemical properties of the fluid are constants and that both acceleration of gravity and viscous dissipation are negligible, governing equations of fluid flow between the smooth plates are continuity (1) and momentum equations $(2-3)$.

$$
\begin{gathered}
\frac{\partial \mathrm{u}}{\partial \mathrm{x}}+\frac{\partial \mathrm{v}}{\partial \mathrm{y}}=0 \\
\frac{\partial \mathrm{u}}{\partial \mathrm{t}}+\mathrm{u} \frac{\partial \mathrm{u}}{\partial \mathrm{x}}+\mathrm{v} \frac{\partial \mathrm{u}}{\partial \mathrm{y}}=\frac{\mu}{\rho}\left(\frac{\partial^{2} \mathrm{u}}{\partial \mathrm{x}^{2}}+\frac{\partial^{2} \mathrm{u}}{\partial \mathrm{y}^{2}}\right)-\frac{1}{\rho} \frac{\partial \mathrm{p}}{\partial \mathrm{x}} \\
\frac{\partial \mathrm{v}}{\partial \mathrm{t}}+\mathrm{u} \frac{\partial \mathrm{v}}{\partial \mathrm{x}}+\mathrm{v} \frac{\partial \mathrm{v}}{\partial \mathrm{y}}=\frac{\mu}{\rho}\left(\frac{\partial^{2} \mathrm{v}}{\partial \mathrm{x}^{2}}+\frac{\partial^{2} \mathrm{v}}{\partial \mathrm{y}^{2}}\right)-\frac{1}{\rho} \frac{\partial \mathrm{p}}{\partial \mathrm{y}}
\end{gathered}
$$

where $\mathrm{u}$ and $\mathrm{v}$ are horizontal and vertical components of fluid velocity, $\mu$ dynamic viscosity of the fluid and $\rho$ its density.

Heat transfer in the channel is described by equation (4), where $\alpha$ is thermal diffusivity of the fluid and T denotes temperature.

$$
\frac{\partial \mathrm{T}}{\partial \mathrm{t}}+\mathrm{u} \frac{\partial \mathrm{T}}{\partial \mathrm{x}}+\mathrm{v} \frac{\partial \mathrm{T}}{\partial \mathrm{y}}=\alpha\left(\frac{\partial^{2} \mathrm{~T}}{\partial \mathrm{x}^{2}}+\frac{\partial^{2} \mathrm{~T}}{\partial \mathrm{y}^{2}}\right)
$$

Fouling model used in this study is the model presented by Jun and Puri [4]. This model is based on the chemical reactions those is subjected $\beta$-lactoglobulin protein from $65{ }^{\circ} \mathrm{C}$ and mass transfer between the thermal boundary layer and the bulk of fluid. When milk is heated above $65^{\circ} \mathrm{C}$, the native protein $(\mathrm{N})$ becomes thermally unstable, it is subject to a chemical reaction of the first order producing an unfolded protein (U) with a reactive sulfhydryl groups (-SH) that generate the polymerization of this protein by a reaction of the second order giving aggregated form (A) of the protein. Chemical reactions take place in the bulk of fluid and the thermal boundary layer. This model is governed by material balance equations $(5-7)$ for each protein.

$$
\frac{\partial C_{N}}{\partial t}+u \frac{\partial C_{N}}{\partial x}+v \frac{\partial C_{N}}{\partial y}=D_{N}\left(\frac{\partial^{2} C_{N}}{\partial x^{2}}+\frac{\partial^{2} C_{N}}{\partial y^{2}}\right)-R_{N}
$$




$$
\begin{gathered}
\frac{\partial C_{U}}{\partial t}+u \frac{\partial C_{U}}{\partial x}+v \frac{\partial C_{U}}{\partial y}=D_{U}\left(\frac{\partial^{2} C_{U}}{\partial x^{2}}+\frac{\partial^{2} C_{U}}{\partial y^{2}}\right)+R_{N}-R_{U} \\
\frac{\partial C_{A}}{\partial t}+u \frac{\partial C_{A}}{\partial x}+v \frac{\partial C_{A}}{\partial y}=D_{A}\left(\frac{\partial^{2} C_{A}}{\partial x^{2}}+\frac{\partial^{2} C_{A}}{\partial y^{2}}\right)+R_{U}
\end{gathered}
$$

where $C_{N}, C_{U}$ and $C_{A}$ are concentrations of native, unfolded and aggregated protein, respectively. $D_{N}, D_{U}$ and $D_{A}$ their diffusion coefficients. $R_{N}$ and $R_{U}$ represent, respectively, unfolding and aggregation reactions, their expression is presented in equation (8) where $E_{i}$ represent activation energies, $n_{i}$ reaction orders and $k_{i 0}$ reaction rates constants. Kinetics constants values are summarized in table 1 .

$$
\mathrm{R}_{\mathrm{i}}=\mathrm{k}_{\mathrm{i}_{0}} \exp \left(\frac{-\mathrm{E}_{\mathrm{i}}}{\mathrm{RT}}\right) \mathrm{C}_{\mathrm{i}}^{\mathrm{n}_{\mathrm{i}}}
$$

The Biot number, $\mathrm{Bi}$, can be calculated by Equation (9). It provides a link between heat transfer and deposition rate where $\beta=129 \mathrm{~m}^{2} \cdot \mathrm{kg}^{-1}$ is an experimental coefficient which depends on plates geometry and $\mathrm{k}_{\mathrm{w}}=$ $10^{-7} \mathrm{~m}^{-1}$ the mass transfer coefficient of the aggregated protein to the wall.

$$
\frac{\partial \mathrm{Bi}}{\partial \mathrm{t}}=\beta \mathrm{k}_{\mathrm{w}} \mathrm{C}_{\mathrm{A}}(0, \mathrm{y})
$$

Finally, the mass deposit at grid position $(0, \mathrm{y})$ can be defined by Equation (10).

$$
\mathrm{M}(\mathrm{y})=\frac{\rho_{\mathrm{d}} \mathrm{Bi}(\mathrm{y}) \lambda_{\mathrm{d}}}{\mathrm{U}_{0}}
$$

where $\rho_{\mathrm{d}}=1030 \mathrm{~kg} \cdot \mathrm{m}^{-3}$ is density of the deposit, $\lambda_{\mathrm{d}}$ its thermal conductivity and $\mathrm{U}_{0}$ the overall heat transfer coefficient at clean conditions. The average mass of the deposit on the plate is expressed by Equation (11), where $\mathrm{W}$ is the width of plate and $\mathrm{L}$ its length.

$$
\bar{M}=W \int_{0}^{L} M(y) d y
$$

Fouling thickness can be expressed from the Biot number as in Equation (12) where h represent convective heat transfer coefficient.

$$
\operatorname{Bi}(y)=\frac{h e_{d}}{\lambda_{d}}
$$

Table 1. Kinetic properties of reactions.

\begin{tabular}{|c|c|c|}
\hline Reaction & Unfolding (N) & Aggregation (U) \\
\hline $\mathrm{n}_{\mathrm{i}}$ & 1.5 & 2 \\
\hline $\mathrm{k}_{\mathrm{i} 0}, \mathrm{~kg}^{1-\mathrm{n}} \mathrm{m}^{3(\mathrm{n}-1)} \mathrm{s}^{-1}$ & $3.4210^{40}$ & $3.2510^{9}$ \\
\hline $\mathrm{E}_{\mathrm{i}}, \mathrm{kJ} \mathrm{mol}^{-1}$ & 276.3 & 79.7 \\
\hline
\end{tabular}


The set of equations (1-7) is resolved by calculation code developed in Fortran 90 language. This calculation code use the finite volume method to discretize each differential equation into set of algebraic equations. Pressure - velocity link is obtained by the use of SIMPLE algorithm of Patankar [10]. The details of numerical procedure, initial and boundary conditions applied in this work can be found in our previous paper [11].

\section{RESULTS AND DISCUSSION}

\section{Numerical Validation}

The fouling model was validated by comparing the computations results with the experimental data from Georgiadis and Macchietto [3] corresponding to the first channel of plate heat exchanger such that milk enters the channel at $60^{\circ} \mathrm{C}$ with a flow rate of $0.833 \times 10^{-4} \mathrm{~m}^{3} \cdot \mathrm{s}^{-1}$. The initial value of walls temperature is $\mathrm{T}_{0}=90^{\circ} \mathrm{C}$. Fig. 2 [11] shows evolution of the average mass of the fouling deposit with time. The mass deposit increases linearly. The relative error between the simulation results and those of experimental data is about $0.66 \%$.

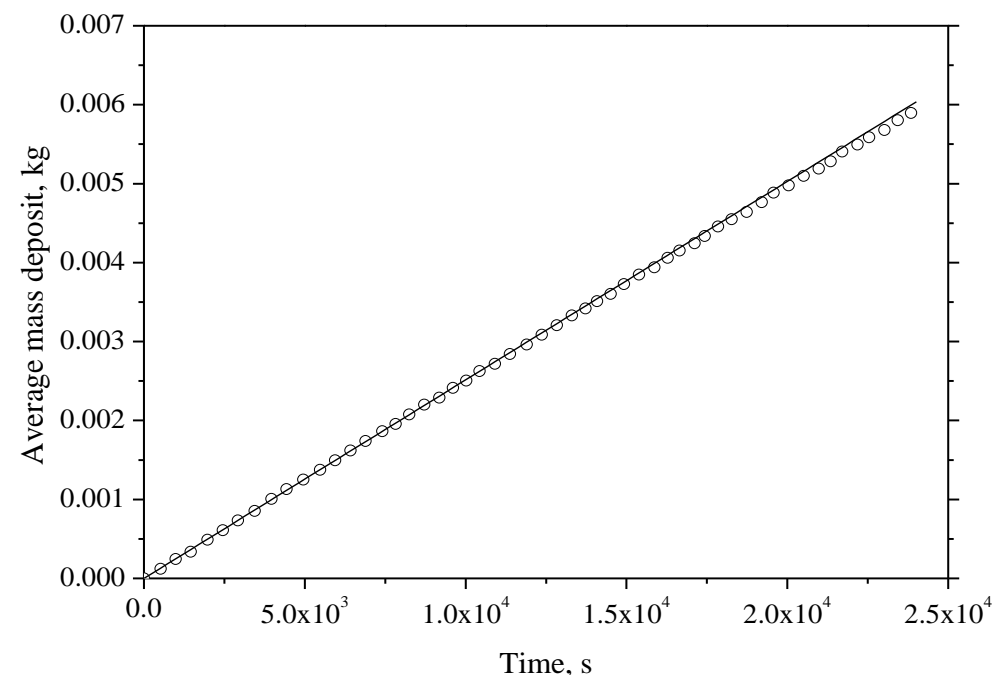

Figure 2. Deposit profiles of simulation results (-) comparison with experimental data $\left(^{\circ}\right)$

\section{Deposit Thickness}

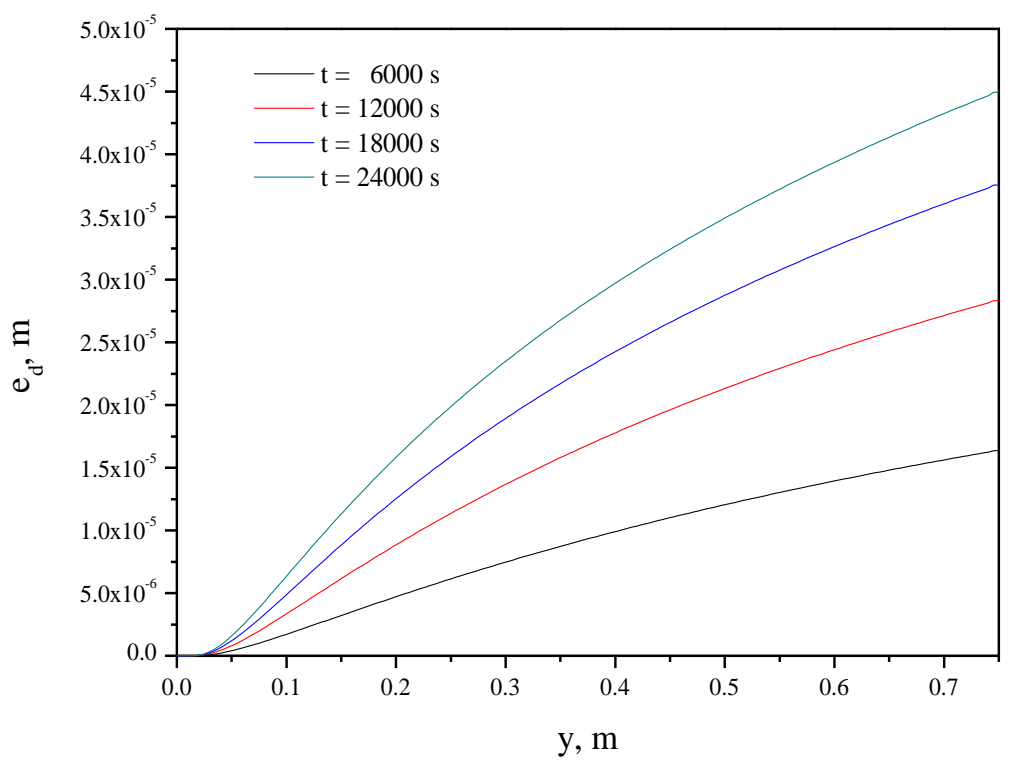

Figure 3. Fouling thickness evolution along channel axis y, during 24000 seconds (four time intervals of 6000 seconds) 
Thermal conductivity of deposits is low, Tissier et al. [12] estimated their value to $0.5 \mathrm{~W} \cdot \mathrm{m}^{-1} \cdot \mathrm{K}^{-1}$. For this reason, thermal performances of heat exchanger are deteriorated. Figure 3 shows the evolution of fouling thickness along the channel wall at different instants of operation. The shape of this distribution is the same for each instant. It is seen that the deposit is negligible at inlet of the channel and it increases along the wall. At the end of operation that lasts 24000 seconds, fouling thickness reaches $0.045 \mathrm{~mm}$. The low quantity of fouling deposited on the wall at the inlet channel can be interpreted by the fact that the temperature required for $\beta$-lactoglobulin denaturation has not reached in this zone. Then, there is no aggregated form of the protein which is deposited.

\section{Wall Temperature Profile}

Figure 4 shows the evolution of wall temperature along the y axis, for four time intervals of operating. Curves have same shape, where the wall temperature remains approximately constant at the channel inlet. Then, it decreases until the outlet.

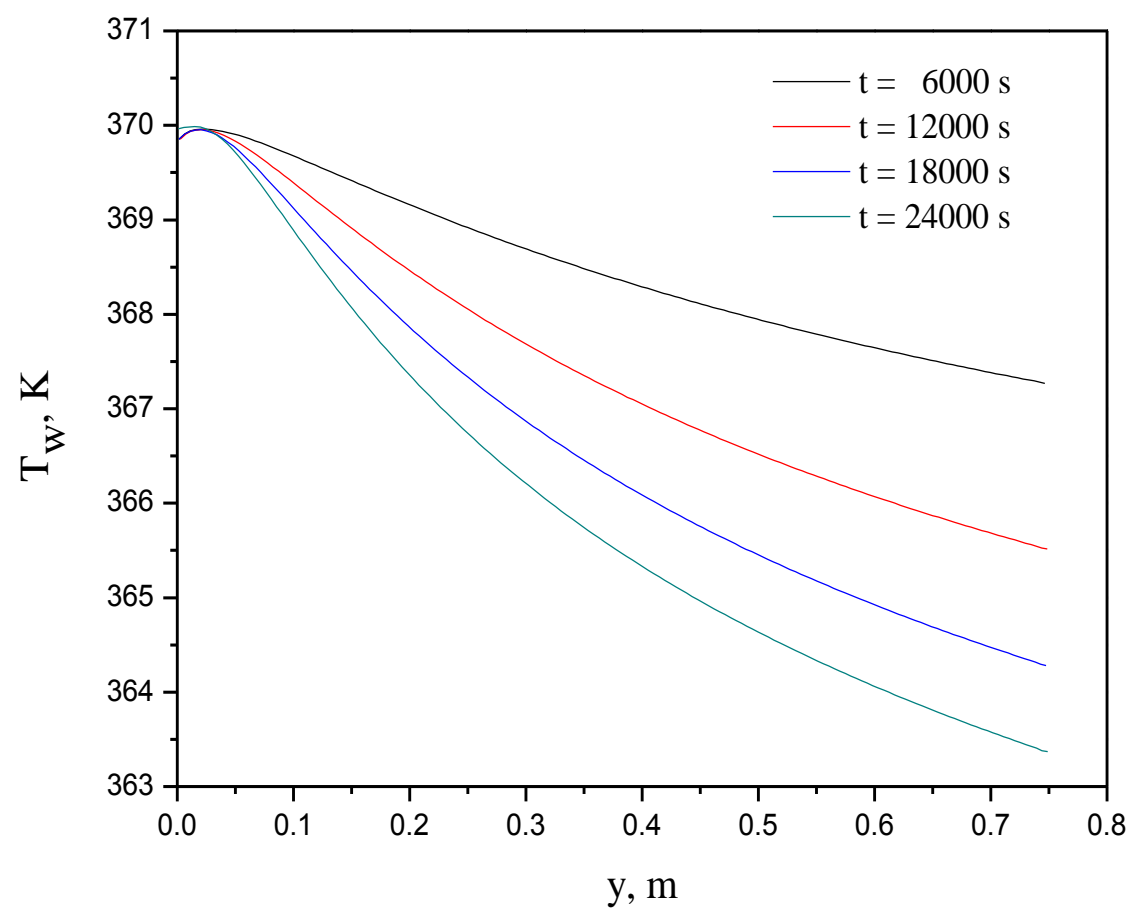

Figure 4. Wall temperature profiles along y axis of channel

This alteration of wall temperature is due to the fouling deposit, which prevents heat transfer towards the bulk of channel. As for the channel inlet, negligible variation of wall temperature can be explained by absence of deposit in this region of channel.

\section{Deposit Thickness on Wall Temperature}

We note that the evolution of wall temperature and deposit thickness profile are strongly related. An attempt to model a mathematical relationship between wall temperature and deposit thickness profiles during milk pasteurization process, is made here. First, wall temperatures upon deposit thickness data are summarized in figure 5 for two different inlet temperatures. Then, an analyze of the fits of each curve is carried out.

We see that curves can be correlated by equation (13) where $\mathrm{T}_{0}=370 \mathrm{~K}$ represent the initial wall temperature at clean conditions, $\mathrm{A}$ and $\mathrm{B}$ are parameters constants. Details of correlation parameters are represented in table 2 . 


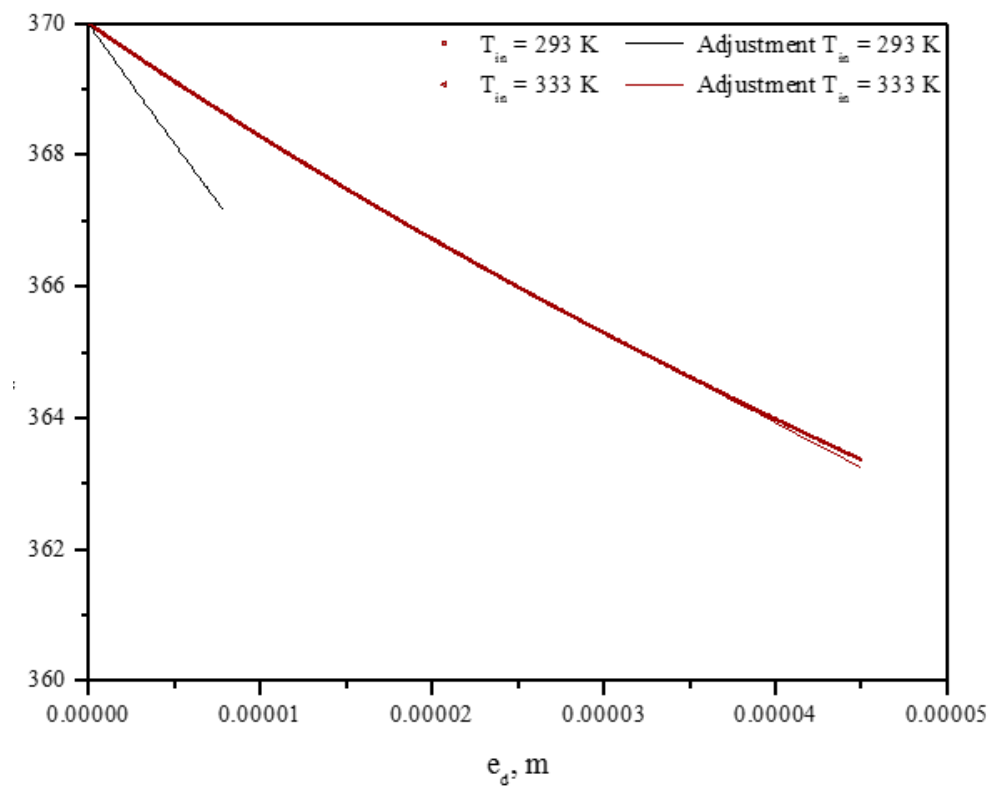

Figure 5. Wall temperature vs. deposit thickness data for $333 \mathrm{~K}$ and $293 \mathrm{~K}$ inlet temperature

$$
T_{w}=\frac{T_{0}}{1+A T_{0} e_{d}^{(B-1)}}
$$

Table 2. Correlation parameters.

\begin{tabular}{|c|c|c|}
\hline Inlet temperature & $293 \mathrm{~K}$ & $333 \mathrm{~K}$ \\
\hline $\mathrm{A}$ & 2.06814 & 0.42001 \\
\hline $\mathrm{B}$ & 1.97876 & 1.90174 \\
\hline Reduced Chi-square & $5.3904610^{-4}$ & $9.11652 \quad 10^{-6}$ \\
\hline
\end{tabular}

The values of parameter $B$ are close for the two cases of inlet temperature. Here, we assume that parameter A depends on denaturation level of $\beta$-lactoglobulin protein and then on the milk inlet temperature.

\section{CONCLUDING REMARKS}

A computational code is used in this work to study the effect of milk fouling deposit on thermal performance of plate heat exchanger's channel. Obtained results shown that the wall temperature is intensely affected by fouling. A mathematical relationship established to define the evolution of wall temperature as a function of deposit thickness. A power function gave better precision, with two parameters. The first one correspond on denaturation level of $\beta$-lactoglobulin protein and the second parameter depend on initial wall temperature. The error obtained by this fitting is about $5 \times 10^{-4}$.

However, in order to generalize the model of milk fouling, we suggest improving this function by introducing milk inlet temperature and denaturation level. Also, a three dimensional model is necessary in order to consider plates geometry. Finally, turbulence must be considered to improve more accuracy of fouling deposit.

\section{NOMECLATURE}

$\overline{\mathrm{M}} \quad$ Average mass deposit, $\mathrm{kg}$

$\mathrm{Bi} \quad$ Biot number

C Protein concentration, $\mathrm{kg} \cdot \mathrm{m}^{-3}$

$\mathrm{D}_{\mathrm{i}} \quad$ Diffusion coefficient, 


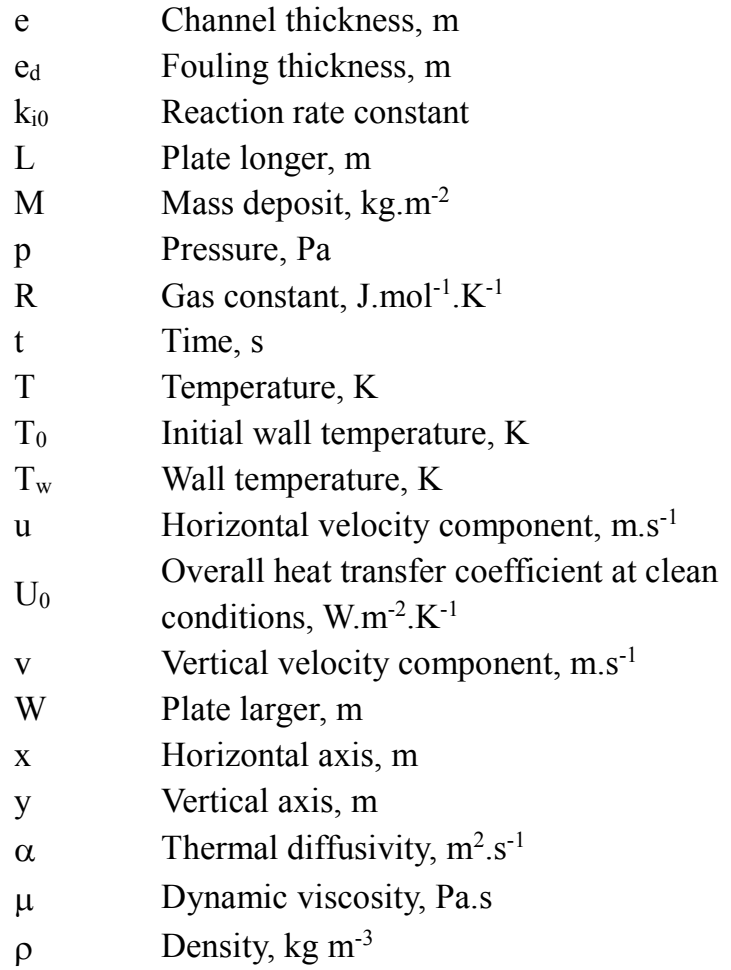

\section{REFERENCES}

[1] Lalande, M., Tissier, J. P. (1985). Fouling of heat transfer surfaces related to $\beta \square$ lactoglobulin denaturation during heat processing of milk. Biotechnology progress, 1(2), 131-139.

[2] Toyoda I., P. J. Fryer (1997). A computational model for reaction and mass transfer in fouling from whey protein solutions, Begell Hou. New York.

[3] Georgiadis, M. C., Macchietto, S. (2000). Dynamic modelling and simulation of plate heat exchangers under milk fouling. Chemical Engineering Science, 55(9), 1605-1619.

[4] Jun, S., Puri, V. M. (2006). A 2D dynamic model for fouling performance of plate heat exchangers. Journal of Food Engineering, 75(3), 364-374.

[5] Mahdi, Y., Mouheb, A., Oufer, L. (2009). A dynamic model for milk fouling in a plate heat exchanger. Applied mathematical modelling, 33(2), 648-662.

[6] Petit, J., Herbig, A. L., Moreau, A., Delaplace, G. (2011). Influence of calcium on $\beta$-lactoglobulin denaturation kinetics: Implications in unfolding and aggregation mechanisms. Journal of dairy science, 94(12), 5794-5810.

[7] Erabit, N., Flick, D., Alvarez, G. (2013). Effect of calcium chloride and moderate shear on $\beta$-lactoglobulin aggregation in processing-like conditions. Journal of food engineering, 115(1), 63-72.

[8] Khaldi, M., Ronse, G., André, C., Blanpain-Avet, P., Bouvier, L., Six, T., Delaplace, G. (2015). Denaturation kinetics of whey protein isolate solutions and fouling mass distribution in a plate heat exchanger. International Journal of Chemical Engineering, 2015.

[9] Bouvier, L., Moreau, A., Ronse, G., Six, T., Petit, J., Delaplace, G. (2014). A CFD model as a tool to simulate $\beta$-lactoglobulin heat-induced denaturation and aggregation in a plate heat exchanger. Journal of Food Engineering, 136, 56-63.

[10] Patankar, S. (1980). Numerical heat transfer and fluid flow. CRC press.

[11] Aouanouk, S. A., Mouheb, A., Absi, R., Zazoun, R. (2017). The behavior of B-lactoglobulin protein in plate heat exchanger's channel during milk heat treatment. Acta Alimentaria, 46(4), 411-419.

[12] Tissier, J. P., Lalande, M. (1986). Experimental device and methods for studying milk deposit formation on heat exchange surfaces. Biotechnology Progress, 2(4), 218-229. 